\title{
Mirrors of Masculinity: Representation and Identity in Advertising Images
}

\author{
Jonathan E. Schroeder \& Detlev Zwick
}

Through explication of a visual research method, this paper theorizes how masculine identity interacts with consumption - of imagery, products, desires, and passions in advertising and consumer culture. We analyze the male body as a discursive "effect" created at the intersection of consumption and several marketing discourses such as advertising, market segmentation, and visual communication, balancing between brand strategy-what the marketer intends - and brand community - the free appropriation of meaning by the market. The paper's contribution rests in extending previous work on male representation into historical, ontological, and photographic realms, providing a necessary complement between understanding advertising meaning as residing within managerial strategy or wholly subsumed by consumer response. We argue that greater awareness of the connections between the traditions and conventions of visual culture and their impact on the production and consumption of advertising images leads to enhanced ability to understand how advertising works as a representational system and signifying practice.

Keywords: Advertising; Imagery; Identity; Representation; Gender; Masculinity

\section{Introduction}

Consumption plays a major role in the construction, maintenance, and representation of male bodies. Almost all products are gendered in a practice of normative sexual dualism reinforced and maintained within the interlocking cultural institutions of marketing communication and market segmentation. As an engine of consumption, advertising plays a strong role in promulgating dualistic gender roles and prescribing sexual identities. Most ad campaigns invoke gender identity, drawing their imagery

\footnotetext{
Jonathan E. Schroeder is Professor, Director of Marketing at the Royal Institute of Technology, Stockholm, Sweden. Detlev Zwick is an Assistant Professor in the Department of Marketing at the Schulich School of Business, York University, Canada. Correspondence to: Jonathan E. Schroeder, Department of Industrial Economics and Management, KTH-The Royal Institute of Technology, S-100 44 Stockholm, Sweden. E-mail: jonathan.schroeder@indek.kth.se
} 
primarily from the stereotyped iconography of masculinity and femininity. ${ }^{1}$ In this way, masculinity and femininity interact smoothly with the logic of the market-advertising representations and consumption practices provide a meaningful system of difference, which has established strong limits to the possibilities of male and female consumer ontologies (e.g., Leiss 1983; Lury and Warde 1997; Nixon 1996). Within this system, iconic masculine activities such as shaving the face, driving fast cars, having a hearty appetite, smoking cigars, and drinking liquor are juxtaposed to feminine visions of applying makeup, driving a minivan, eating "light," doing the laundry, and decorating houses.

This paper analyzes the cultural construction of masculinity via a look at the male body and its visual representation in advertising. We focus on the way contemporary images express and inscribe a number of contradictory conceptions of masculine identity. We bring ontological considerations to bear on advertising imagery, that is, how representation, consumption, and identity intersect to construct, maintain, and circulate conceptions of masculinity via advertising imagery, segmentation strategies, and the logic of the market. We place contemporary advertising imagery into a historical context that encompasses photography, fine art, and graphic design within what we call a visual genealogy. We emphasize how ads produce and manipulate social signifiers rather than how individuals appropriate their symbolic value (cf. Ritzer 1998).

Through explication of a visual approach, in conjunction with recent work in critical consumer research, we theorize how masculine identity interacts with consumptionof imagery, products, desires, and passions in advertising and consumer culture. Representations do not merely "express" masculinity, rather, they play a central role in forming conceptions of masculinity and help construct market segments such as the New Man, playboys, connoisseurs, and lads, in the British vernacular (see Elliott, Eccles, and Hodgson 1993; Kuhn 1982; Mort 1996). We analyze the consuming male body as a discursive "effect" created at the intersection of consumer practice and several marketing discourses such as advertising imagery, product availability, and market segmentation strategies. Moreover, we situate consumer identity within the philosophical concerns of identity, drawing on several theorists to develop the notion of ontology in contemporary advertising (e.g., Borgerson 2001; Borgerson and Schroeder 2002; Butler 1990, 1993; Gordon 1995, 2003). Somewhat novel in considerations of "surface" issues like popular culture and advertising imagery, our deployment of “depth" analysis highlights the importance we place on advertising roles within contemporary intellectual debates, such as subject construction, representation, and gender. We attempt to balance on the line between structuralism and poststructuralism, drawing theoretical perspectives informed by poststructural developments, but insisting on some cultural and historical qualifications that ground our interpretative work.

Our contributions center around three interrelated concerns. First, we add to recent analyses of masculinity in advertising within research on consumer identity that signals a growing awareness that masculinity, like femininity, is constructed, codified, and contested within marketing imagery. Often, research on gender in advertising and consumer culture emphasizes femininity and female identity, which may inadvertently suggest that femininity is constructed in ways that masculinity is not, as well as foster 
ontological links between female identity and consumption. We interpret masculine images in contemporary ads as particularly useful sites of identity formation and contestation. In other words, advertising images provide partial answers to the question "What does it mean to be a man?" (Stern 2003). Second, we develop an understanding of consumption via our focus on representation as social signification, particularly as it relates to basic issues of identity and its connections to consumer goods. We draw on interpretive methods, as introduced in the consumer behavior literature by Scott (1994), Stern (1993) and others (e.g., Hirschman 1989; McQuarrie and Mick 1999; O’Donohoe 2000; Stern and Schroeder 1994). However, visuality is often overlooked within consumer research and marketing scholarship (cf. O'Guinn 2004; Schroeder 2002). Third, we present an interdisciplinary matrix that draws on philosophy, consumer research, and visual studies to approach complex issues in consumption, markets, and culture, placing previous work on male representation into historical perspective, thus providing (missing) conceptual links between advertising as managerial strategy, on one hand, or as creative consumer reading, on the other.

We begin with the notion that masculinity is - semiotically-irrevocably connected with, opposed to and in relation to femininity. We pose questions in relation to the larger socio-cultural meaning of advertising images, in particular struggles over the representation of gender and gender roles within gendered target markets, and argue that advertising imagery constitutes ubiquitous and influential bodily representations in public space, incorporating exercises of power, surveillance and normativity within the consumer spectacle. We focus on gender relations and gendered relations, rather than on difference per se, and pay particular attention to bodies and bodily representations. We suggest that advertising imagery helps provide consumer solutions to gender tensions and struggles over representing idealized masculine consumers, in particular the crisis of masculinity.

An art historical approach grounds our analysis, focusing attention on how the male body has been historically portrayed and the way this genealogy colors representational conventions in contemporary advertising. A visual viewpoint illuminates advertising representations infused with visual, historical, and rhetorical presence and power. First, we briefly review the representation concept within consumer research, then introduce an ontological perspective that frames our theoretical approach. We discuss several key antecedents within the historical genealogy of bodily representations that we believe are essential in understanding contemporary conceptions of male body images. Then we present in-depth analyses of contemporary print advertising images as a departure point to analyze how they conflate sexuality, masculinity and consumption in the fulfillment of desire. At a basic level, these images visually represent a shift from men as producers to men as consumers. The examples, drawn from influential magazines like Time, The New York Times Magazine, and The New Yorker, are meant to be illustrative, not representative, iconic, and not typical. Whereas these publications target particular market segments - and indeed the ads help construct and develop these segments-we are more interested in the subject as embodied within the ads themselves than the consuming subjects the ads target. In this way, we join recent research that considers ads as cultural artifacts as well as managerial tools. We speculate 
on various interpretive stances for these images, providing an expansive reading grounded in visual analysis. We close with a discussion of advertising interpretation and its relation to constructions of masculine identity, as well as broader representational issues within consumer research.

\section{Advertising, Consumption and Representation}

The analytic approach presented here makes three interrelated assumptions about advertising images. First, ads can be considered aesthetic objects. This assumption acknowledges the creativity and thought that goes into the production of most national advertising campaigns, and how consumption has become aestheticized via style, fashion, and integration into what has been called the art-culture system (Lury 1996). Second, ads are socio-political artifacts. These two categories-aesthetic and politicalare often constituted as mutually exclusive. Our analysis attempts to locate advertisements within a complex visual signifying system that includes the inter-related aesthetic and political domains. Third, we situate advertising within a system of visual representation that creates meaning within the circuit of culture-often beyond what may be intended by the photographer, advertising agency or commissioning company. This "circuit" assumes that advertising both creates and contributes to culture (Hall 1980). Our interdisciplinary visual method does not necessarily compete for authority with other approaches. Instead, it represents a useful, distinct level of analysis, particularly suited to sorting out meaning construction in visual images (see Bordo 1997; Hall 1997; Leiss, Kline, and Jhally 1990; Schroeder and Borgerson 1998; Stern and Schroeder 1994).

Advertising discourse both reflects and creates social norms. As one critic points out: "the ways in which individuals habitually perceive and conceive their lives and the social world, the alternatives they see as open to them, and the standards they use to judge themselves and others are shaped by advertising, perhaps without their ever being consciously aware of it" (Lippke 1995, 108). In other words, advertising representations influence cultural and individual conceptions of identity, and must be understood as the result of changing social and cultural practices. Consequently, our overarching framework views meaning — in advertising as well as art-as the result of historical contingencies. We are concerned with recent developments in representing masculinity, influenced by the women's movement, shifting patterns of labor participation (for both men and women), relaxing standards, at least in the West, of representational norms, and sophisticated, focused target marketing that often isolates and codifies consumer identity.

Research on advertising representation commonly focuses on the internal content of advertisements - what the ad claims, how it links the product to consumer benefits, or the design of the ad. These are important issues. However, advertising also acts as a representational system that produces meaning outside the realm of the advertised product (e.g., Goldman 1992). For example, the production of taste remains one of advertising's most important objectives. The close relationship between social class and taste has diminished during the rise of consumer culture, interfering with people's 
ability for "naturally competent selection" of appropriate products, practices, and preferences (Bourdieu 1984; Holt 1997).

Many contemporary ads make little mention of the advertised product or service. Visual arrangements are such that the advertised good often drops into the background while highly abstract connections are made between the models, a lifestyle and the brand. Viewers are asked to transfer meaning from the look of the people in the adtheir image, lifestyle, and physical appearance-onto the product (Williamson 1978). Important contributors to meaning are art historical referents that inform and influence-consciously or not-the creation and reception of the ad (Schroeder 2002).

Sociologist Erving Goffman pointed out that ads impact directly on lived experience by normatively limiting our conceptions of identity, right and wrong, and the good life (1979). Critically, ads influence how we think about masculinity and femininity, what is sexy, and what will be seen as attractive by desired others (see Schroeder and Borgerson 2003). Goffman showed that "every physical surround, every box for social gatherings, necessarily provides materials than can be used in the display of gender and the affirmation of gender identity" (1997, 207). Standard advertising poses generally signal men's dominance over submissive women, be it through physical, financial, or psychological superiority (Kolbe and Albanese 1996; Nixon 1996; Schroeder and Borgerson 1998). By focusing upon behavior as performance he challenged the distinction between the image and lived experience. Goffman's dramaturgical metaphors for understanding representation in social interaction have been influential, particularly within contemporary gender theory (Tseëlon 1995). His work paved the way toward Judith Butler's influential philosophical analysis of identity; Goffman prefigured the discourse of performativity and gender (Butler 1990, 1993).

\section{Masculinity and Representational Practices}

Advertising images have typically drawn upon clear cultural categories to depict gendered consumer selves: "advertising agencies have to learn, then employ, quite specific cultural vocabularies as a precondition for advertising specific consumption practices to particular consumer groups [...] Ad agencies must acquire knowledge of consumers' symbolic meaning-systems in order to invest the advertising development process with its culturally meaningful potentiality" (Hackley 2002, 215-16). However, signs of "transgression" have appeared on the representational horizon. Contemporary ads that depict men's bodies in compelling and provocative ways suggest a change in the limits posited by the traditional male gaze of advertising.

In a recent article, Maurice Patterson and Richard Elliott discuss male representation in advertising, and argue that some contemporary images "invert" the male gaze. Men are increasingly encouraged to view their own bodies as sites of identity management: "consumers" bodies are the products of labor (body work) that necessitates consumption and the use of consumer goods, and simultaneously, through visualization, their bodies act as advertisements for such labor" (Patterson and Elliott 2002, 234). They claim that advertising representations of the male body responded to feminism in part by reinscribing masculine identity via the man's man, or lads, typified by 
new male lifestyle magazines like Maxim, Men's Health, and Gear, that have aggressively revived stereotypical male tropes of babes, brawn, and beer.

Furthermore, they suggest, this inversion of the male gaze provokes psychological reflection: "when the gaze is turned on itself, men are more likely to move through a range of responses such as rejection, identification and desire" (Patterson and Elliott 2002, 241). This stance corresponds with Hirschman and Thompson's model of advertising relationships, emulation, criticism, and personalization (1997), where rejection functions similarly to criticism, identification to personalization, and desire to emulation. It remains unclear whether the inverted gaze causes these reactions in men. Perhaps the larger process of constructing men as consumers-of which the inverted gaze plays an important part-ultimately influences male responses to advertising images. Patterson and Elliott conclude that hegemonic masculinity adopted to recent societal changes with "the increasing feminization of masculinities, as men are encouraged to partake in the carnival of consumption, to become concerned about their appearance, to get in touch with their emotions, and as male bodies become objects of display subject to the male gaze" (Patterson and Elliott 2002, 241). Of course, many upper-class men have long been concerned with their appearance; and for certain men-actors, politicians, models_-looks remain a particularly salient feature of identity. We contend that the gaze has expanded, rather than inverted. A look at the broader historical context of male representation helps clarify and contextualize their important study.

Our approach focuses more on visual issues within male representation; we sketch a visual genealogy of images concentrating on the cultural production of codes, apart from managerial intent and consumer interpretation. We turn to allied fields of philosophy, visual studies, and art history for insight into visual theory and representational practices. We ask, what are the visual and cultural factors that inform contemporary advertising images and brand campaigns? We believe that branding and advertising researchers, who focus more heavily on corporate strategy on one hand, and consumer response on the other, often overlook these issues. These are important considerations, but each needs to be contextualized within culture (e.g., Hall 1997; Schroeder 2002; Scott 1994; Stern 1996; Weiss 1999). To understand the role of these complex cultural processes, we must delve into marketing's ontological underpinnings. In this endeavor, we concur with Holt's recent assessment that "such knowledge doesn't come from focus groups or ethnography or trend reports — the marketer's usual means for 'getting close to the customer'. Rather, it comes from a cultural historian's understanding of ideology as it waxes and wanes, a sociologist's charting of the topography of contradictions the ideology produces, and a literary critic's expedition into the culture that engages these contradictions" (Holt 2003, 49). To which we would add, a philosopher's engagement with the historical and theoretical significance of representation and identity, and an art historian's knowledge of the visual genealogy of representational practices.

We do not mean to suggest that we will take an imperial view of images, dictating what and under what conditions they mean certain things to consumers. Rather, we sketch the visual genealogy of contemporary images, focusing on three salient historical 
referents, in a process that Richard Sennett describes as postholing-digging deeply into several points in a historical continuum and using these as a basis for theoretical work (Sennett 1977). Our postholes include the iconography of the fine art portrait, the nineteenth-century rage of carte de visite portraiture, and the less popular, but perhaps more long-lasting tradition of male pin-up photography. Throughout the paper, we privilege the visual as a manifestation of consumer and male desire.

We acknowledge that we are working with a restricted domain of masculine identity, circumscribed by the West, centered on the US and its mainstream media, and bounded by race and class. Gender politics are changing, many people resist sexist stereotypes, and there now exists a myriad of gender identities (cf. Schroeder 2003; Thompson and Haytko 1997; Thompson and Hirschman 1995). Furthermore, masculinity is a specific cultural construction - a fiction, but one with political effects (Burgin 1996). However, despite the potential for transgressive readings, we contend that cultural messages within the advertising discourse still function largely to reinforce traditional gender roles and to limit the consumer body to conservative forms of masculinity and femininity. Thus, if we can isolate the building blocks of masculine identity, we can begin to think critically about the power discourse of advertising in constructing the masculine (consumer) body. We are then able to illuminate the limits advertising imposes onto the possibilities of male ontologies but also, how these limits shift within culture and across time.

\section{Identity}

Much previous research has discussed how advertising messages often restrict representations of the consuming body by limiting and structuring possibilities of masculine and feminine consumption (e.g., Barthel 1988; Elliot, Eccles, and Hodgson 1993; Goldman 1992; Kates 1999; Nixon 1996; Schroeder and Borgerson 1998; Stern 1993). One result is that advertising representations create mechanisms that simultaneously reinforce and (partly) conceal traditional notions of gender relations, that is, ad imagery often makes gender roles seem transparent, natural-just there (Goffman 1979). Recent work on issues such as the inverted gaze, oppositional readings, queering imagery, and consumer resistance reveal the complex, contradictory power of advertising imagery, leaving open possibilities for change.

Theory from many disciplines struggles to understand how hierarchical dualisms in the arenas of class, culture, gender, and race function ontologically when contingent social and psychological constructions nevertheless define and limit embodied human identity (cf. Borgerson 2001, for a review). These dualisms, although contested and culturally influenced, have not disappeared (cf. Bourdieu 2001; Butler 1990, 1993; Connell 2002; Gordon 1995, 2003). Despite gender bending, queering, and androgyny, gender remains a fundamental social, psychological and cultural category. We acknowledge that our starting point inhabits Western society in the present moment, but we draw on theory that contends that these dualisms are pervasive, and tend to objectify social relations and identity categories such as gender (cf. Miller 1995). Repeated, or reiterated, versions of gender and race underlie and continually revitalize 
what is considered natural, typical and, often, appropriate for specific groups. Stereotyped and, perhaps, damaging, representation of iterations derived from essentialist, often sexist and racist, understandings remain a crucial concern for research into advertising images.

Michel Foucault's late writings found him preoccupied with a form of philosophical concern that he describes as a "critical ontology of ourselves" (1984, 45). Throughout his genealogical work, Foucault $(1977,1978)$ argues that we are constituted as modern subjects through a nexus of several historical power discourses such as medicine, criminology, education, and psychiatry. One of the more important features of discourses is their articulation and employment of limits. These limits enclose the ontological identity of the individual through installing a series of binaries distinguishing self from other, identity from non-identity (i.e., masculinityfemininity, cultured-primitive, sane-insane, and so forth). As a result, limits restrict the set of possibilities open to self-formation. The most important implication of limits is the constitution of the "normal subject." (Not to be misunderstood as a universal concept of Platonic sorts.) Foucault argued that within each discursive formation such as the medical field, the prison, or the psy-sciences unique processes of normalization govern the production of desired and deviant subjects (Rose 1995, 1997). Instead of one universal "normal" form, several "normalities" co-exist depending on the discursive field. Common to all fields however, is that the desired or normal subject fits neatly into the "right" one of the binary categories, for example the white middle-class, the straight, and the law-abiding citizen (versus the black, the homosexual, and deviant citizen), the rational consumer (versus the irrational consumer), or the soccer mom (versus the welfare mom) (Dumm 1993; Firat, Sherry, and Venkatesh 1994; Gordon 1995; Zwick and Andrews 1999). Furthermore, masculinity-in a semiotic sense-lines up with each right category: rational, normal, law-abiding, and so forth: "masculinity, for example, in a philosophical tradition that values rationality, is associated with a superior ability to reason, femininity with a denigrated intuition of emotion" (Bartky 2002, 70). In this way, any behavior that falls outside the limits of normalized ontologies becomes obscure, deviant, and almost incomprehensible, with respect to the specific formations of the self (Gordon 2003).

The notion of limits enlightens representational practices and their capacity to reflect or produce ontological change. Outside structuralism, more subtle investigations of power discourses become possible, allowing us to reject overdetermined fixations of meaning. For example, an analysis of the representational language of advertising inspired by Althusserian structuralism would be unable to explain any change in the politics of representation if the social and institutional structures of advertising production had not equally changed. In other words, as long as the structural dialectic of class (labor-capital), race (black-white), or gender (female-male) remain intact, no change can occur because it is exactly this system of classification that orders what is thought, practiced, and represented (Bourdieu 1992). On the other hand, any structural change in the relations of advertising production or binary coding would axiomatically command representational change. 
The concept of limits breaks with this kind of determinism and allows for the possibility of complex discursive interactions within institutional and binary codes. Indeed, taking this approach we can now analyze advertising representations as texts produced at the intersections of representational conventions, changing definitions of target markets, and cultural politics of gender among others. It must be noted that we do not wish to downplay the importance of institutional power structures at work within the advertising industry to understand meaning production. In fact, in a very real sense the opposite is true. We take advertising's masculine hegemony as a given (cf. Hanke 1992). This strategy allows us, rather than concentrate on advertising as information or marketing strategy, to focus on how other discourses are employed to contest or secure the production of meanings in advertising. The analytical immanence of our analysis is supported by the success of Foucault's powerful genealogies that he described as writing "a history of the present." To conduct a visual analysis of contemporary advertising representation of course means to consider historical antecedents of the modern advertising discourse. In this way, we undertake what we call a visual genealogy-an excavation of representational practices, perceptual processes, and cultural codes that inform contemporary advertising imagery.

\section{Visual Genealogy and Contemporary Advertising Images}

To place contemporary advertising images of masculinity within a historical framework, and to develop conceptual links between disparate forms of representation, we turn to art history and closely related fields of visual studies and photography. Art critic John Berger described important parallels between the history of art and advertising, showing how advertising depends heavily on the techniques, symbols, and history of paintings (Berger 1972). In general, art is a sign of affluence in Western cultures-it belongs to the good life. Advertising drew on the language of painting that celebrates wealth, power, and private property, and art, in turn was influenced by the commercial world and its graphic techniques and popular subjects (e.g., Drucker 1999). Moreover, advertising shaped the modern era, with its insistence on visual consumption.

\section{Photography and Portraiture}

In the US, advertisers quickly took advantage of print technology to link ads to art, paintings were used in advertising images for their attractive bright colors and appealing cultural associations (Marchand 1985). Artistic references also suggest a cultural authority superior to crass material interests (Berger 1972). Thus, by referring to art, advertising can simultaneously denote wealth and spirituality, luxury and transcendent cultural value. In particular, advertising mobilizes formal artistic conventions of portraiture-pose, symbol, style_as well as techniques borrowed from painting, photography and film to represent identity (Lears 1994; Pelfrey and Hall-Pelfrey 1993; Sturken and Cartwright 2001).

Photography emerged as advertising's primary medium (see Goldman and Papson 1996). Photography, like advertising, has deep ties to fine art: "much of the formal 
iconography and symbolic structuring has its roots in painting, but photography substitutes for the painting's presence a veracity and immediacy which, in going beyond questions of aesthetics, involves us in what has been called 'the entwined problematic of representation and sexuality"' (Clarke 1997, 123). Graphic design, film, and fashion also extend their influence on advertising imagery and practice; however, the largely hidden structure of photographic definition and discourse remains understudied as the dominant information technology of marketing imagery (see Schroeder 2002). Photography subtly occupies the public space of representation, establishing and maintaining identity in visual representation.

Photographs encompass both a critical part of the advertising world and an important process of representing identity. Historically, photography allowed many more people the opportunity to possess an image of themselves. Photographic portraits, in particular, are perhaps the most straightforward representations of identity (Tagg 1989). Yet the very artificiality of most portraits-smiling, touched up, well lit, posed-demonstrates a gap between image and lived experience. Much of the difficulty in apprehending and interpreting photography lies in the medium's surface realism. We must remind ourselves that advertising models in ads are posed, paid, and pampered-despite their "natural" appearance, advertising images "are not 'reality' but an artfully arranged manipulation of visual elements. Those elements are, however, arranged precisely to arouse desire, fantasy, and longing, to make us want to participate in the world they portray" (Bordo 1997, 122). Furthermore, photographic conventions, while often appearing natural and spontaneous, evolved within the historical context of visual representation: "superficially, at least, the photograph is directly opposed to the portrait painting, and yet it is extraordinary how the portrait photograph remains encoded within the context of paintinghence the complexity and contradictions at the heart of any photograph of an individual" (Clarke 1997, 103). Advertising portraits build upon these representational conventions.

Marketers appropriated, transformed, and harnessed photography to create a dominant communication technology. However, advertising images contradict Roland Barthes's influential notion that photography shows "what has been" (1981). As consumers we should know that what is shown in ads has not really been; ads are usually staged constructions designed to sell something. Yet, largely due to photography's realism, combined with aesthetic and technological expertise, advertising images produce powerful, persuasive simulations of a real world.

Portrait photography_like figure painting — manifests a larger politics of power and representation articulated within the social psychological process of the gaze. To gaze implies more than to look at-it signifies a psychological relationship of power and sexuality in which the gazer dominates the object of the gaze. For example, film has been called an instrument of the male gaze, producing limited representations of women, the good life, and sexual fantasy from a male point of view (Mulvey 1989). Royalty gaze upon their subjects, viewed as property in the kingdom. Explorers gaze upon newly "discovered" land as colonial resources (Pratt 1992). Tourists gaze upon the exotic other, encountered on packaged tours (Urry 2002). Interpersonally, the gaze 
"corresponds to desire, the desire for self-completion through another" (Olin 1996, 210). The gaze, then, limits both the gazer and the gazed upon. Patterson and Elliott's inverted gaze represents one of the myriad forms that the gaze may take, including a female gaze (see Clark 2000; Mosse 1996; Sturken and Cartwright 2001).

\section{The Carte de Visite}

Social historian Andrea Volpe's $(1999,2000)$ work on the role of nineteenth-century carte de visite (visiting cards) in the formation of an American notion of desired middle-class bodies offers a concrete example of photography's complicated interaction with consumption, the gaze and the represented body. Cartes de visite offered a relatively accessible, portable, and lifelike portrait to the masses, and comprised 95 percent of photographs made during the nineteenth century (Bender 1982). The representational and aesthetic shifts that ensued with the success of cartes de visite offer important insights into the mass production and consumption of photographic images, and serves as a crucial step in the development and deployment of human portraits in advertising.

As the first form of photographs printed on paper, cartes could be cheaply multiplied. Their small size made them portable and the use of posing stands that held the posing subject in perfect position for the shot enabled the photographer to produce cartes de visite in rapid quantities (Volpe 1999). Economically, they were an instant success, albeit less because of the demand originating from the upper social classes to have their picture taken, the initial target market for cartes. The real economic impact was generated by the vivid exchange of cartes de visite in urban and later even rural places of America. Millions bought and sold photographs showing individuals of whom they often knew nothing about, not even their names. The cultural implications of this trucking and trading of cartes de visite cannot be underestimated. The carte de visite, Volpe argues, created a powerful visual discourse of the body (1999). Because of the rigid regime of the posing stand, men and women portrayed in the cartes took on standardized "ideal" body postures during the long exposure times. Consequently, a socially and culturally respectable type of the body quickly emerged, reproduced and circulated. The quantities in which cartes de visite were multiplied and discharged into the marketplace ensured a wide diffusion of these body representations and their ensuing high visibility. In a short time span, a previously "bodiless" middle-class became embodied. Moreover, the middle-class subject also becomes gendered and raced through the same representational force.

Suren Lalvani's study of photography's role in constructing modernity shows how nineteenth-century photography, including cartes de visite, functioned to discipline the body. From studying popular forms of nineteenth-century photography, he concluded: "in legitimizing specific forms of subject-object relations, technologies of vision like photography, embedded within particular discursive and cultural formation, organize specific relations between knowledge, power and the body" (Lalvani 1996, 2). He reminds us that portraiture-like pornography and advertising-exists for public display even if it is intended for private consumption (Lalvani 1996). 
The carte de visite produces ideal representations of the "normal" subject: middleclass, white, and male or female, respectively. The desirability of these bodies was reinforced through their juxtaposition with the spectacular bodies of the "abnormal" other. Women without arms, blacks with deep complexions and "unrefined" facial traits, and midgets came to be featured on cartes and were equally successfully commercialized in the nineteenth-century marketplace as representations of grotesque bodies (Bajac 2002). So, two decades before the printing press acquired the technical ability to reproduce photographs in newspapers, cartes de visite had laid the ground for social, cultural, and ideological categories of the normal body. Their aesthetic and formal aspects were both deeply rooted in the conventions of fine art and normative for the future representation of men and women. As such, they can be seen as a key intercessor between fine art and modern forms of media representation such as advertising, which relies heavily on pictures of people, constructed as consumers, employees, managers, or "typical people," echoing the phenomenal success of cartes de visite as aesthetic consumer objects, personal possessions, and social signifiers.

Like advertising imagery, cartes de visite offered up images of the known and the unknown for consumption, circulation and scrutiny, helping usher in the image economy. They were among the first mass circulated images of identity, exerting a profound influence on photographic reproduction, codes of appearance, and the visual imaginary (Bajac 2002). Celebrity carte de visite portraits were incredibly popular, helping pave the way for today's obsession with celebrities' images in magazines, websites, television, and supporting their lucrative roles as product endorsers. Furthermore, they impressed upon their large audience an awareness of physical appearance, instilling a reflexive concern with body, identity, and posterity.

\section{The Male Pin-up}

The male pin-up is another form of portrait that informs contemporary male advertising imagery, one that helped clear the path for recent masculine representational terrain - the bods, hunks, and heartthrobs of mainstream media. In a classic study of male representation, Richard Dyer extended Goffman's gender analysis to the male pinup genre-which includes celebrities, actors, athletes, gay icons, and pornography. His close analysis of pose, posture, and gaze point out important features of contemporary masculine representation, within an expanding visual repertoire of men's bodies.

Dyer suggests that images of men that are specifically designed to be looked at, admired, and worshipped, such as celebrity portraits and male pin-ups, unsettle patterns of the gendered gaze, producing "a certain instability" (1982). For example, he found that representations of men as sex objects, or at least celebrities, generally show men looking off to one side or up, thus not facing the camera lens. He notes that in social interaction women look at men more, in part as a result of listening and generally paying attention to them. Women watch men, in other words (Dyer 1982). However, in crowded situations, men watch women, often gazing at them without social interaction. In male photographic poses, he points out that looking off camera suggests an interest in something outside the range of the viewer's vision. Looking up may imply 
an interest in something more important than his face or body, an "upward striving" that resolves some of the contradiction between masculine identity and male object of desire. Furthermore, male models rarely look at the viewer. When then do, they rarely smile as women do so invitingly. Looking and the gaze usually implies power, those with permission (and time) to look are generally more powerful than those looked at. Looking signals activity, being looked at, passivity.

A standard motif in Western advertising is the "hero" shot—an ad containing an image of a lone man, conquering some territory, villain, or at least underarm odor. A single man within an image — without a family, wife, or other heterosexual markersalso allows for a "gay" reading (e.g., Clark 2000; Kates 1999; Schroeder and Borgerson 2003; Wardlow 1996). This contradiction involves “the apparent address to women's sexuality and the actual working out of male sexuality" (Dyer 1982, 66). How do images of men resolve this issue? How to maintain gendered power relations while representing men as objects of desire? Dyer contends that images of men "must disavow this element of passivity if they are to be kept in line with the dominant ideas of masculinity-as-activity" (Dyer 1982, 66). Thus, men are often shown doing something, or with an identity defined outside that of a pin-up, such as a sports star or businessman (cf. Schroeder and Borgerson 1998).

\section{Visual Genealogy and the Consumer Context}

These "postholes" — portraits, cartes de visite, and pin-ups—provide a historical background for understanding contemporary male imagery. As visual theorist Anthea Callen argues, "visual images are, then, potent mediators of the lived experience of the body, our own and others, giving us ways of conceptualising and describing the bodily" (Callen 2002, 603). These three genres cannot exhaust the genealogical influences upon contemporary advertising images; rather, we point to the rich historical backdrop that informs current consumption and production. Furthermore, we are not implying that all consumers consciously acknowledge how these genres may inspire current ad campaigns, or even that art directors and photographers actively appropriate prior representational forms. We suggest that these forms circulate through culture, exerting both direct and indirect influence on the production and consumption of imagery. Direct, via training, as many ad producers study the history of visual representation; indirect, via the iteration of images over time, space, and generations within fashion, retro, and camp cycles. Pierre Bourdieu argued that fine art traditionally provided a taste-making vehicle par excellence. We suggest that advertising performs much the same function today, contributing to its status as cultural discourse (see also Marchand 1985). In the next section, we discuss how contemporary imagery struggles with emerging conflicts over representational form, masculine identity, and desire.

\section{Contemporary Contradictions in Representing Masculinity}

Many researchers have suggested that recent advertising images have reflected-or anticipated — transformations in ideals of masculinity (e.g., Elliott, Eccles, and Hodgson 
1993; Mort 1996; Stern 2003). As gender theorist Robert Connell puts it, men "face structurally-induced conflicts about masculinity-conflicts about their sexuality and their social presences as men, about the meaning of their choice of sexual object, and in their construction of relationships with women and heterosexual men" (Connell $1992,737)$. We join this focus on masculine identity, and ask questions about how it is constituted and what forms it takes. What do contemporary visual representations say about masculinity? How does transformation within ads express contradictions and conflicts about male identity? How might they reflect tensions between self and other, desire and desiring, modernity and postmodernity? How does (the fear of) homosexuality influence advertising representation?

Surely, gender identity "is a pervasive filter through which individuals experience their social world, consumption activities are fundamentally gendered" (Bristor and Fischer 1993, 519). Products are designed for girls or boys from the first breath, and gender segmentation is understood by consumers as young as two and three (Pennell 1994). Yet, consumer desire is regularly assigned agency - an active choice toward gendered goods. According to one popular consumer behavior textbook, lifestyle marketing "recognizes that people sort themselves into groups on the basis of the things they like to do, how they like to spend their leisure time, and how they choose to spend their disposable income" (Solomon 1999, 147). How one sorts oneself into masculine or feminine-one of the basic identity groups-poses an intriguing question; most consumers do not "choose" their gender identity in the same way as they join an online chat forum, sports fan club, or professional association (see, of course, Butler 1990, and especially 1993). Thus, consumer choices about clothing, hairstyle, piercings and sexual products all contribute to the construction of sexuality, lifestyle and identity (Schroeder 1998a). Masculinity represents one such distinct lifestyle, associated with, and continuously constructed by, consumer behaviors such aggressive driving, shaving, gift-giving, or investing (see Sturrock and Pioch 1998).

We consume gender identity with our eyes, bodies, and minds (see Willis 1991). Men, in particular, are socialized (at least in the West) to rely on the visual sense for arousal. Sight remains the most distancing of the senses, "in which the subject stands separate from the object, which is other, there" (Young 1990, 182). This is the power of the gaze. Controlled by its discursive limits, the gaze orders sexual possibilities thereby constituting gendered identities: male-female, subject-object, desiring-desired, sexually dominating-sexually dominated. The world of advertising largely reinforces these limits chiefly through its well documented, yet enduring, sexist representation of women, but also via limiting images of men (e.g., Barthel 1988; Bordo 1993; Brod 1996; Goffman 1979; Schroeder 1998b; Stern 1993; Williamson 1986).

The gaze usually turns toward female bodies. Images of women permeate society; part of being male apparently involves consuming female images, in a pedagogic ritual of consumer culture that generally reaffirms the heterosexual imperative in which attractive, readily available women serve as sexual, zestful objects of desire. In short, within conventional advertising representations the male embodies the active subject, the business-like, self-assured decision maker, while the female occupies the passive object, the observed sexual/sensual body, eroticized and inactive. However, some 
recent commercial images seem to disrupt the dominant gaze suggesting shifting limits of the advertising discourse.

Several cultural contradictions occupy current representations of masculinity in contemporary advertising. First, within the feminized consumption realm, how might men be represented as consumers, without diminishing their power? Second, how might the male body function to represent consumer goals, such as success, attractiveness, or the good life? Third, in what way can male desire be shown, without collapsing into typical projections of the female body?

In the next section, we assess three contemporary advertising exemplars that articulate this set of contradictions, providing illustrative examples for reflecting on masculinity, ontology, and desire. The ads were drawn from popular magazines, and feature mainstream products, alcohol and automobiles - two of the biggest players in the advertising industry. These examples were assembled specifically to illuminate the article's themes, as well as for their compositional connections, which we discuss below. We found them useful images to develop our ideas about advertising representations of identity. We do not claim that they are representative, rather we argue that they are meaningful, compelling images worthy of close analysis. In this way, we follow interpretive work that focuses on a limited range of materials in order to make broader points about representation and identity in visual materials (e.g., Gombrich 1999).

\section{Marketing the Man}

\section{Coloma Licor de Cafe}

"She was impressed that he ordered their Mudslides with Coloma. Which did wonders for his self-confidence" states a recent print ad for Coloma " $100 \%$ Colombian Licor de Cafe." This ad features a black and white photograph of a white man and woman at a bar or restaurant table with a superimposed color photograph of a Coloma bottle next to a lowball glass that presumably contains a Mudslide $(1 / 2 \mathrm{oz}$. Coloma, $1 / 2 \mathrm{oz}$. Irish Cream, $1 / 2$ oz. Vodka, 1 oz. cream). The color inset floats on a red circle, circumscribed by a yellow line. The product name, spelled out in brown writing, represents the brand's two Os with stylized coffee beans. Coloma, "the smoother way to stir things up" reads the copy's double entendre, an oblique innuendo for its purported ability to "smoothly" stimulate desired interactions, "stirring things up" apparently standing in for alcoholically propelling people together.

The action takes place in an oval, gilt-framed mirror hanging to the left of the couple. The bespectacled man gazes at his reflection, which has curiously transformed him into a much more classically attractive visage. In the mirror's reflection, the man appears to be in his mid to late twenties, tall, dark, a rakish curl of hair falling seductively down his forehead. He wears a dark jacket over a bright white dress shirt, unbuttoned at the neck to reveal a neat, white T-shirt. He sports a carefully pressed and folded white handkerchief in his left breast pocket. He has lost "his" eyeglasses, pointed nose, unstylish hair, and oversize chin-he might be said to resemble Pierce Brosnan as James Bond. The woman-not caught in the reflection that we see-seems to be peering 


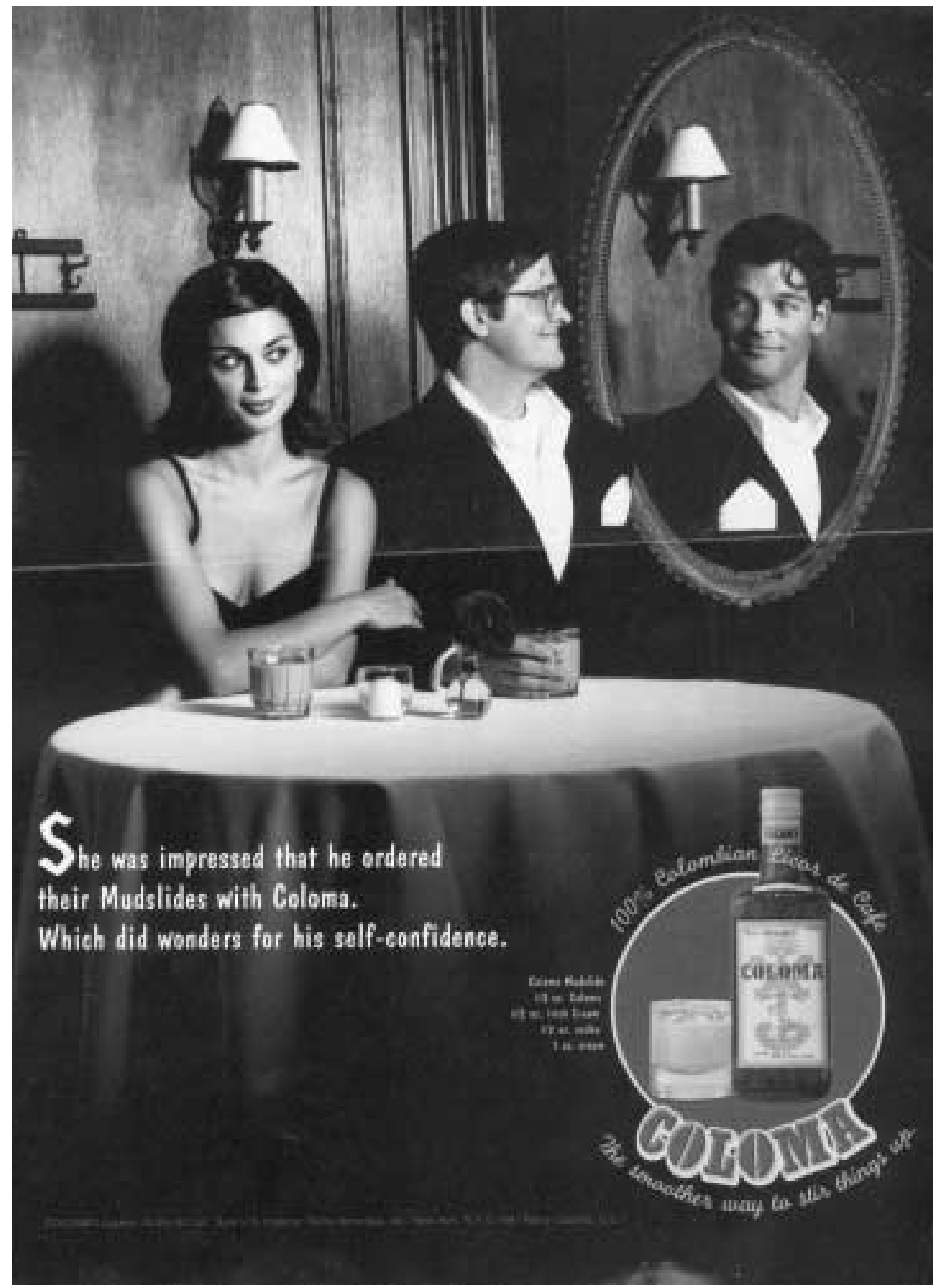

Figure 1 Coloma Licor de Cafe advertisement.

across her companion to look at his rugged reflection. She models a low cut cocktail dress, which reveals a thin frame, a conservative, shoulder-length haircut, and makeup that exaggerates her facial expression—one of bemusement. She seems secure in her 
effect on her companion. She appears to be enjoying herself-her right arm reaches over and grasps the man's right arm. A lit votive candle and a small vase with a romantic rose grace their table. Her drink sits in front of her, untouched. His right hand curls around his Coloma Mudslide, maintaining its fetish-like powers of transformation.

We suggest that the ad represents a portrait of a male-female couple with the addition of another male peering in on them from behind the mirror. This mirrored image may be read in several ways, as the sage from whom the man learned the ways of ordering impressive drinks, or the self transformed by demonstrating taste. To order and consume the right product (even the choice of the restaurant) expresses the man's cultural capital in the field of middle-class consumer culture. Thus, the ornamental femininity of his date further enhances his capital accumulation, and her apparent pleasure at his beverage brand reaffirms his masculinity, attractiveness and taste in one go. Perhaps more attractive mirror-man admires less attractive man's drinking partner, thus conferring male status on his ability to attract a desirable date? The alchemical mirror embodies contradictions of the consuming male; one must be vain and attractive, as well as rational and sophisticated.

Furthermore, the tropes of alcohol involve taste, the pleasures of imbibing, the ability to "control one's liquor," and, at a more fundamental level, a ritual of adulthood, especially the male variety. In Bourdieu's theory, the conversion of one form of capital into another is precisely what makes it so valuable to vie for various forms of capital in different social fields. Here, we see the conversion of cultural capital into social capital by virtue of acquiring more desirable "body-for-others" (Bourdieu 1984, 207). Either way, we have a provocative message of physicality and product use.

The "homely" man seems caught, Narcissus-like, gazing at his more handsome reflection, looking away from his date. Mirrors are a traditional trope of vanity, narcissism, lust, and pride in Western art. Usually, mirrors are linked to women, revealing, reflecting, and reinforcing feminine attributes of beauty and vanity. In this ad, the mirror plays a double role-casting a reflection of the newly self-confident man, and echoing the female role of mirroring male identity. Thus, the feminine mirrors the masculine, reflecting back self-confidence, consumer expertise, and embodied transformation. Furthermore, the woman stands in as a mirror. He looks to her to gain a flattering conception of himself-she was impressed which did wonders for his self-confidence. This process is reminiscent of Charles Horton Cooley's concept of the looking glass self, whereby we construct our identity by how others reflect back to us (Cooley 1902). The male gaze turns toward the female as well as the mirror to reassure himself of his competence, attractiveness, and confidence. She touches him, reminding him of her presence, her mirror-like qualities, but she is otherwise unengaged with him. His reflection represents his narcissism, as well as his insecurity.

This ad stands out for its representation of the male gaze, and suggests a reordering of limits within the male discourse. The image appears to invert, or perhaps expand, the object of gaze; the man seems quite concerned with himself as an object of beauty, as he vainly pays more attention to his image than to his date. But unlike the genuinely self-confident beau of conventional gender displays, the man in the ad is not handsome and doubts his effect on the woman. He must labor to impress her. Of course, Coloma, 
via the association from product to person, comes to his rescue; it allows him to display refined taste and transforms him into the more "typical" man. His self-doubts fadethanks to the woman's positive impression-his masculinity reaffirmed. However, one might read this ad in other ways, as men to men, perhaps the striking man in the mirror attracts the gaze of the homely man, doubly disrupting the gaze, and transforming the ad into a potentially gay image (see Kates 1999; Stern and Schroeder 1994). This queer perspective finds homoerotic overtones in the gaze between the two men-one reflecting, one reflected-who wink at themselves while wooing others.

\section{Lexus LS 400}

"Introducing a Lexus for Those Who've Never Seen Themselves in a Lexus" states a recent ad for Lexus automobiles. In the center of the ad, a man stands with his back to the viewer, facing what looks like a large indoor billboard advertisement for Lexus. His right arm hangs down at his side, his left firmly placed on his hip. His well-toned physique exhibits a desired, vigorous "V" shape that signals a regular regimen of body care and concern. He wears black pants and shoes, his slicked back hair shimmers with a silvery, sensuous gleam. Oh, and he is naked from the waist up. Our hero appears to be in a subway station, waiting for the next train. A payphone hugs the ad's darker far right edge. On a bench at the left, his briefcase and copy of the Wall Street Journal rests, placing him firmly within the managerial milieu, and symbolically providing him with an identity outside his potential pin-up pose.

The ad image within the image shows a Lexus LS 400 moving swiftly from right to left, its rear end blurred by speed. Curiously, we can see the car through the man's back-his transparent and ethereal body provides a vehicular vision. The iconic "transporter" technology from Star Trek comes to mind-his body looks as if it were fading into the billboard photograph of the car. (A turn to art history reveals ancestors of this technique, especially in landscape painting.) The billboard's metallic silver frame circles the man's waist, resembling a high-tech belt. This line binds him into the frame of the photograph, as if including him within the frame, wrapping around his wrists, as well. He is thus dressed by the image, joined to it - apparently caught by an ad in the subway, one of many he encounters in an average day. This ad, however, seems to literally draw him in, binding his body to the image. His back projects into the ad, merging with it, serving as a window and a screen for the viewer. The product projects onto him, and he seems to be absorbing the message bodily. His body has become the ad's medium, representing the product by incorporating it bodily, a spectacular instantiation of the consuming body.

This ad plays upon a number of visual conventions. The man clearly gazes at an image. The scene resembles a museum-goer gazing at a famous painting, reminiscent of surrealist Rene Magritte's famous series of images Man in the Bowler Hat that depict a man with his back to the viewer. One way to read the image suggests that he nowliterally- "sees himself in a Lexus." Lexus here represents a trope of managerial masculinity, a success symbol that powers him out of his current predicament. His surroundings are human-made, the often inhospitable public realm of mass transportation. In a 


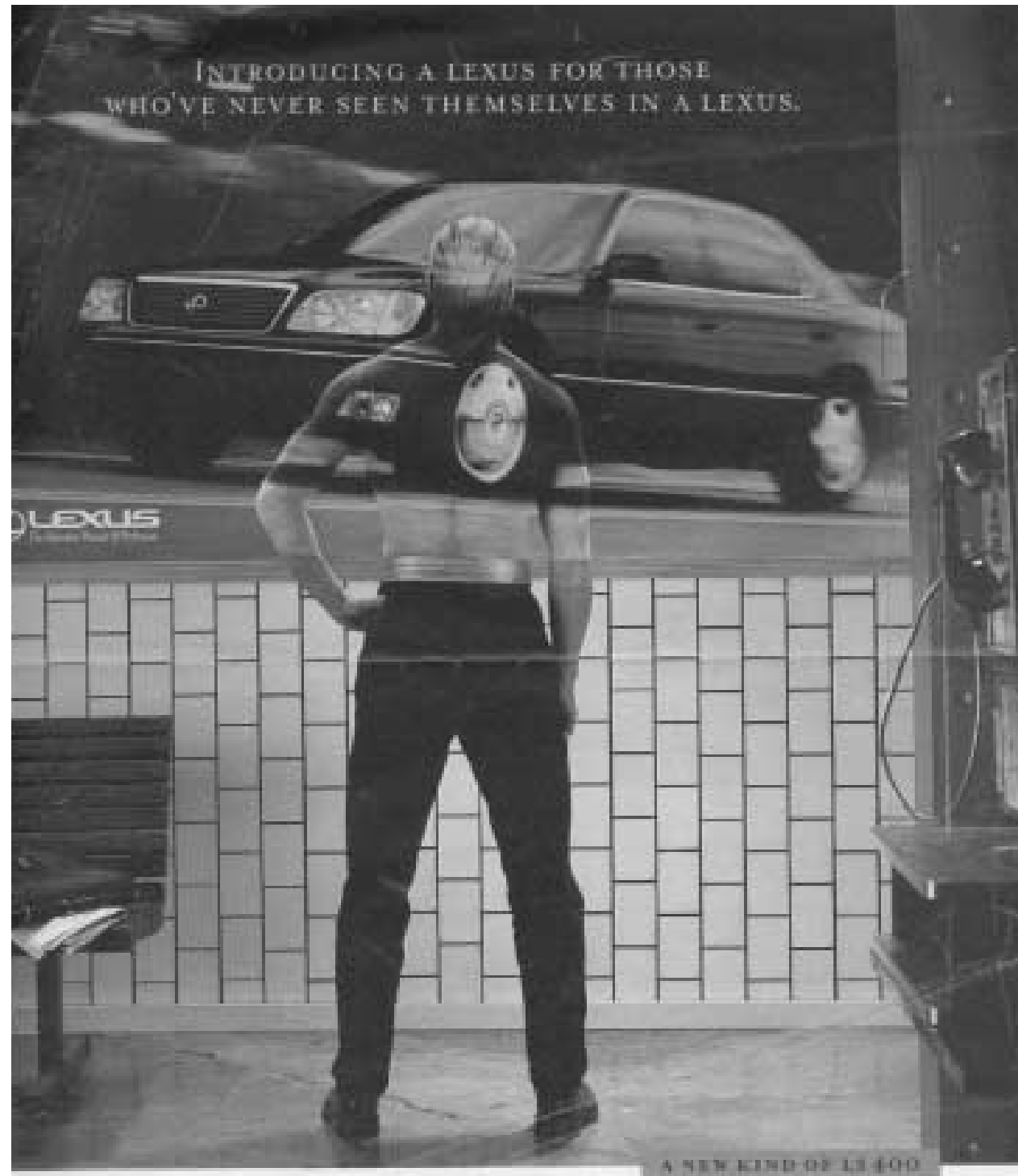

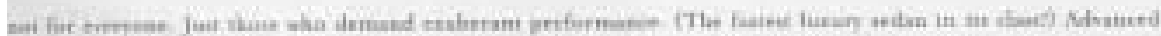

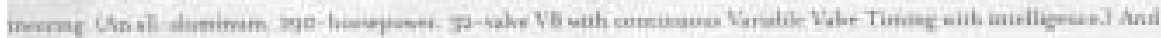

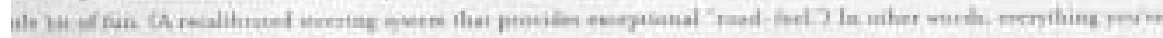

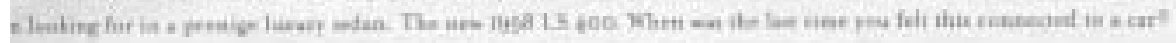

Figure 2 Lexus LS 400 advertisement.

Rousseauian sense, his partially nude form might signal a desire to return to a more natural state, a state of being he could be in if he were not burdened by culture. Ironically, the car represents the escape from culture-from reliance on mass transit, from business clothing, from alienation. Instead, man's natural state heeds his desire for 
independence, individuality, control over one's own life, and sexual prowess. The copy reads "When was the last time you felt this connected to a car?" Thus, the man in the ad connects to the car, physically, visually, psychologically, suggesting the naturalistic fusion of two bodies in sexual rapture. Indeed, the car has become part of him, the wheel hovering near his heart, the engine near his head, in a high-tech escape from the iron cage of modernity.

In this ad, some limits of conventional advertising discourse are shifted. The man in the ad, while remarkably virile (see his muscular body and assertive stance), loses his sober distance, his objectivity. He surrenders emotionally and physically to the visual experience. The car, now becomes part of the man, his self-extension (Belk 1988), or perhaps vice versa; being in a Lexus an important part of his reverie. The ad challenges the "natural" view of man as controlled, self-sufficient, and rational subject. Rather, the ad expresses a synthetic male personality assembled out of the flotsam and jetsam of contemporary commodities (Mort 1996).

Moreover, the ad shifts limits of traditional discourse in that it focuses on the aesthetics of the male body. With his back to us, he displays his well-built, nude torso, a stylish hairstyle, and close-fitting, tailored pants. His shirtless appearance marks an anomaly. Although female bodies are constantly displayed in this manner in advertisements, a male body thus depicted remains rather unusual, at least until recently. Recall, though, his managerial identity, signified by briefcase, Wall Street Journal, as well as his Lexus fascination provides him with "cover," he is not merely a model. Clearly, we can make visceral and sensual connections between his and the car's body-power, performance, exceptional "road-feel" but also elegance, softness (colors), and taste. His body, as the conduit of the product's image and the ad's message, constitutes a hybrid, caught in between the masculine and feminine, battling domestic containment that the subway represents, longing for the Lexus escape.

\section{Oldsmobile Aurora}

"Defy Convention: Allure" shows an Oldsmobile Aurora automobile parked in front of an elegant corner antique store. Atop the curved building sits a billboard, lit from below, advertising " $\mathrm{d} 2$ couture: Milan, NYC, Paris" on which a man and a woman embrace each other. The man's closed eyes signal his enjoyment. However, the woman looks away-out of the ad frame-toward the Aurora parked on the street below the billboard. The man, intent on kissing her neck, seems not to notice the "outside" scene distracting her. She wears an elegant dress or gown. His clothes are less remarkableindeed his body seems to shrink from view. Her hand animates the image, placed carefully, yet forcefully, on his shoulder, almost as if she is starting to push away. The billboard "ad" within the ad oozes high fashion and status, reinforcing the general look of the pictured location as an upscale shopping district—where an Aurora owner would feel at home.

The headline-Allure-signals perhaps the woman's appeal, but more significantly, the advertised car's qualities: "aerodynamic steel skin, carved haunches, and a sculpted tail." Clearly, the ad references bodily qualities, as well as to the cultural qualities 


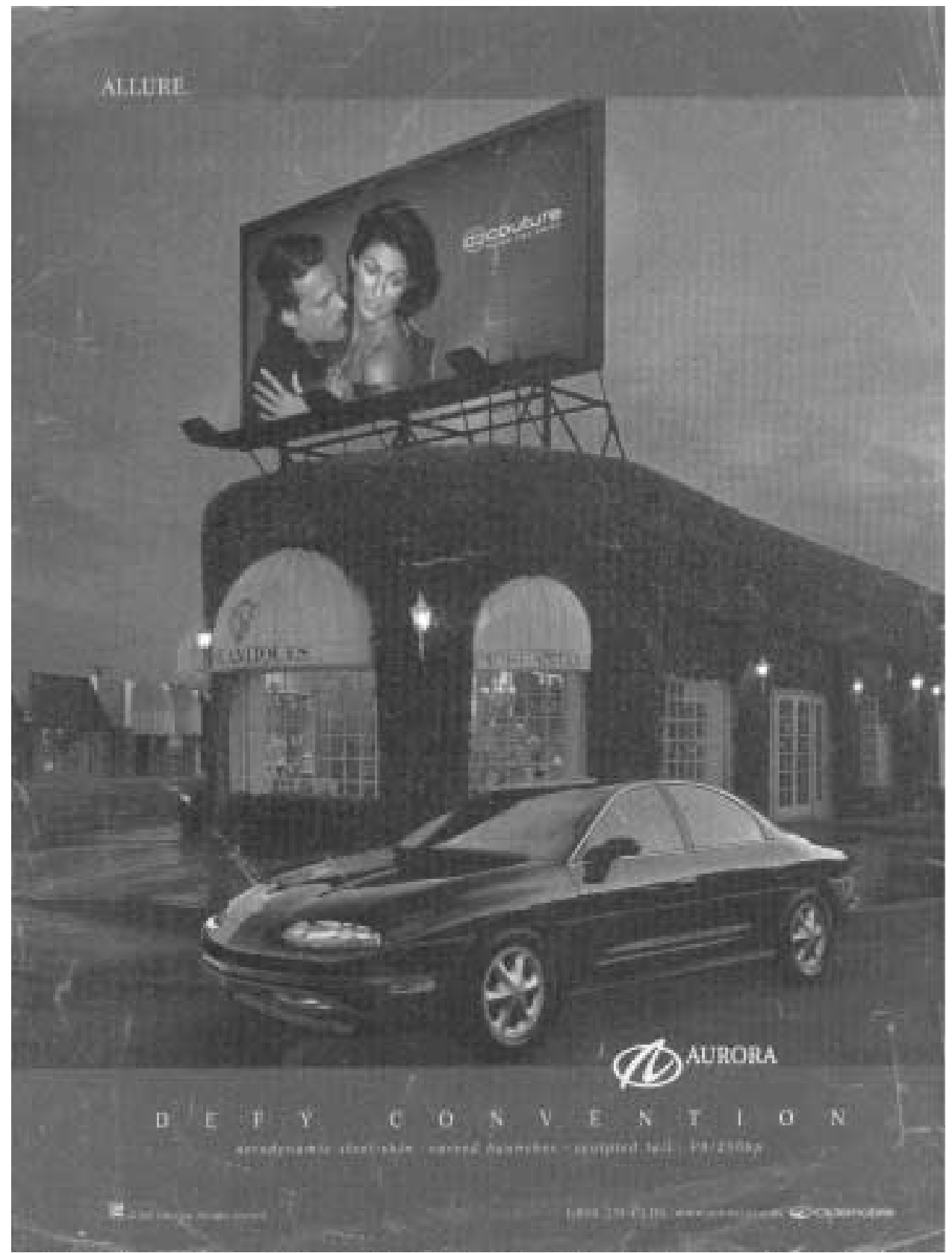

Figure 3 Oldsmobile Aurora advertisement.

embodied in the shop's antiques, the street's quaint architecture, and the new car's shiny surface. "Allure" rarely describes men. However, it seems that by catching the woman's eye the car embodies desirable male traits, allowing it to compete with her kissing partner. 
The man's presence in the billboard serves to inscribe the ad's gendered relationships. In an apparent defiance of convention, the woman seems more attracted to a car than a man. The automobile, an epitome of commodity fetishism, transforms the women's possibility for social relations as the commodity stands in for a man. However, read in another way, the image disrupts the assumption of heterosexuality present in most mainstream ads. The woman turns away from the male toward the product, shifting the gaze within the ad, rejecting the man in favor of the machine. From a male point of view, it seems we now must compete with consumer goods for attention, facing the novel prospect of being replaced by a newer, more stylish (product) model. The Olds enjoys more appeal, or at least attention, than her date, subtly reinforcing the gendered notion that women, not men, choose mates. Consumer culture has empowered females to make choices, become active agents (albeit limited by the market), and even question entrenched notions of heterosexuality. The woman in the ad challenges convention by rejecting the embodied male. Viewed this way, Aurora truly isn't "your father's Oldsmobile."

The Olds Aurora represents a newer, better model-one to trade up for. Traditionally cars have inhabited the female realm as objects of male desire. Furthermore, automobiles have been associated with females via the use of advertising models, car show models and media. Perhaps now a car is implicitly read as female, eschewing the need for an actual female model, making the car more malleable as an iconic statement of identity. Thus, this ad shows its interpretive flexibility: aimed to men the message reads "she'll be attracted to you in your Olds;" aimed to women, "your allure allows you trade up for a better model." Frankly, we find these messages rather confused, and wryly note that General Motors recently discontinued the Oldsmobile brand.

As women are seen as an expanding target market for expensive consumer goods like automobiles, products will be given different qualities within the gendered world of mainstream products. To create women as serious consumers, they must be represented in typical male roles: decisive, financially and emotionally independent, egotistical. Indeed, in no subtle terms, the ad encourages the woman to commit the original sin. Like Eve, the woman's devotion leaves the confines of her world within the billboard (which presumably should be focused on the man) and tested against the seductiveness of the material object. Confidently, she ignores the man and "reaches" for the car. The (al)lure of the product has usurped the male, thereby hailing new possibility for women's moral freedom and economic power.

Complex and traditionally technological products, automobiles have long been given human-like traits and design features-body, nose, headlights like eyes and so forth (Berger 1998). Rather than ascribe male qualities to the car, the copywriter fell back to animal qualities as a proxy, thus opening up possible reading outside the realm of heterosexuality. In this ad, however, these qualities loom as threats to men's relationships with women. We have created an adversary, it seems, that magically awakens a photographed woman with its bodily allure. To be sure, the ad does not go so far as to proclaim the end of the masculine-feminine divide. But for the modern woman, the ad suggests, masculinity is a floating concept with sliding meanings: she finds it in men as 
well as objects, such as automobiles. But maybe she is not much interested in masculinity at all.

Another way to frame this image is via the notion of "window dressing;" the subtle placing of gay "signs" within an otherwise heterosexual tableau. Thus, the woman's rejection of the man for the car - a feminized object - may be read by those so inclined as a rejection of heterosexuality, and a turn toward a lesbian relationship or at least encounter. In the two other ads, as well, window dressing possibilities abound: the lone Lexus man resembles a pin-up, a gay ideal, a shirtless hunk; and as discussed, the Coloma men may well exchange queer looks. Each image contains crossover potential, pointing out the flexibility inherent in marketspace bodily representations.

\section{Shifting Gaze—Shifting Limits}

These three ads are not meant to be a representative sample. We chose them instead for their interesting manner of representing male bodies-as illustrative exemplars of shifting images of men and the gaze in contemporary ads, and their visual deployment of transitional tropes such as the mirror, the portrait, and the figure. Taken together, we believe they show the male body as subject of the gaze-not necessarily a female gaze-participating in the world of product advertising as well as a shift in the heterosexist gendered consumption of the gaze itself. Furthermore, these unrelated ads refer to the consuming gaze of advertising images. The Coloma and Lexus ads focus on the body represented by male bodies. The Aurora ad, we argue, projects embodiment onto an automobile, and shifts the gaze away from the heterosexual male. This machine represents an interesting hybrid, perhaps the logical articulation of advertising strategy that links human qualities with products. In a remarkable way, the car has the power to animate a still life in a surreal transformation from image to being.

These ads each feature an image within the image - a mirror, a subway ad, and a billboard that represents the body, reflecting the (promised) transformational power of products. Each expresses a formal condition of representation that visual theorist Nicholas Mirzoeff calls intervisuality: "the simultaneous display and interaction of a variety of modes of visuality" (2002, 3). Each assumes a way of representing the consumer gaze, and activating psychological processes of identification, looking, and desire, much as paintings of paintings, mirrors and the figure serve allegorical purposes in Western Art. As attributes of truth, mirrors do not lie. Mirrors also have iconographic connections to sight, pride, vanity, and lust - a potent package of signifying potential (Hall 1979). For example, mirrors serve as symbols of isolation and visibility, recall the Narcissus myth that trapped him forever within a mirror's gaze. Thus, the mirror (as well as the ads as mirrors) isolates consumer's attention upon their own body within the marketing framework, making identity visible, trapping them within longings for immortality and transformation. In the Coloma ad, the male body is transformed via ordering an impressive product. Thus, product use can make up for physical "deficiency." The Lexus also physically transforms the male model. He is rendered ethereally transparent, signaling his escape from the scene as well as his connection with the automobile. In the Aurora ad, the product assumes bodily form; 
human qualities are projected onto the Oldsmobile, which attract a woman nearby. The Aurora-body exudes allure, a quality embodied in its design and carefully cultivated for its brand image.

Each ad can also be read as gay. We are not suggesting that these mainstream producers are embracing the gay market, nor were these images found in media directed at gay consumers. Rather, they seem to take energy and inspiration from gay iconography, perhaps as a way to unsettle ad conventions. Or, in an attempt to portray men as attractive consumers, gayness seeps in, an occupational hazard when utilizing attractive male models. We note that homosexuality is not built on a lack of masculinity, rather it is intertwined with hegemonic masculinity (Connell 1992). Consumption offers a solution, a way to navigate the boundaries between homosexual identity and heterosexual culture, or perhaps a way to express homosexual longings without engaging in homosexual relations. Thus, consumption, or at least representation of consumption, shifts hegemonic masculinity from the realm of aggression, bodily force, competition, and physical skill to the domain of consumption, including taste, discernment, expertise, and bodily appearance (see also Miller 1998; Stern and Schroeder 1994). We see ads as transformative guides or "a journey between milieux" (Connell 1992, 748).

It seems reasonable that queering these images opens up further possibilities for male identity, albeit still circumscribed by mainstream notions of masculinity and male desire (cf. Kates 1999). Thus, the male may gain an awareness of his own body as a site of desire, as indicated by Patterson and Elliott (2002). Judith Butler suggests that "desire is intentional in that it is always desire of or for a given object or Other, but it is also reflexive in the sense that desire is a modality in which the subject is both discovered and enhanced" (Butler 1999, 25, emphasis in original). Thus desire brings about the relationship between image and viewer, between product and consumer, between object of desire and the desiring subject: "in effect, we read our negativity in the objects and others we desire; as desirable, detestable, solicitous, or rejecting, these emotional facts of the world mirror our ontological insufficiency in Hegelian terms; they show us the negativity that we are, and engage us with the promise of plentitude or the threat of reaffirming our nothingness" (Butler 1999, 9-10). Via consumption, or the promise of plentitude, consuming subjects exercise ontological dilemmas.

Advertising discourse is shifting its limits. Perhaps not a fundamental challenge to conventional male ontologies, but new possibilities are opening up. The Coloma ad subtly suggests that good looks and good taste (and not the conventional money and power nexus) are now also part of male attractiveness; a new standard from which men had hitherto been relatively exempt. The Lexus ad creates a hybrid, synthetic male, who submits helplessly to the attraction of desire and fantasy. Far from being "in control" and "rational," he shows emotions freely. Finally, the Aurora ad, man is pitched against (and possibly ditched for) a car, his identity commodified as commodity fetishism takes over, his body dispensed of as the car displaces him.

So, although limits extend, and the gaze expands, gender relations remain oppositional. Male representations have changed in the last few decades, but male dominance 
remains. In a sweeping study of Playboy magazine and its affect on male gender roles, one writer concluded: "masculine identity and visual codes premised upon youthful hedonism and conspicuous consumerism certainly ruptured and displaced the traditional codes of a bourgeois masculinity rooted in ideals of hard work, thrift and puritanical conservatism. But, at the same time, they left wider power structures and systems of inequality essentially intact" (Osgerby 2001, 203-04). However, we argue that to the degree that the advertising discourse animates visual consumption processes (Schroeder 2002), a change of its discursive limits disrupts traditional conventions of the male gaze and opens new possibilities for male identities.

\section{Conclusion}

To interpret advertising images is to acknowledge their representational power both as cultural artifacts and as bearers of meaning, reflecting broad societal, cultural, and ideological codes. We need to keep in mind that photographs-particularly advertising photographs_-are not mere pictures, accurately representing some external world: "the photograph both mirrors and creates a discourse with the world, and is never, despite its often passive way with things, a neutral representation" (Clarke 1997, 27-28). Our interpretations are meant to suggest possibilities, both in terms of what we take as intended messages as well as resistant meanings. Images, saturated by a long cultural history, constitute an engaging and deceptive culturally and historically bound visual language system. Advertising imagery-as a subset within this system-interacts with it, borrowing from and influencing the larger world of visual culture.

Constructing a visual genealogy of contemporary images helps illuminate how advertising works as the face of capitalism, harnessing the global flow of images, fueling the image economy. This work balances between brand strategy-what the marketer intends - and brand community - the free appropriation of meaning by the market. We point to the cultural, historical and representational conventions that limit both encoding and decoding interpretation processes. Greater awareness of the associations between the traditions and conventions of art history and the production and consumption of advertising images may lead to a better understanding of how these representations constitute a discursive space within which a meaningful sense of the male body can be maintained. As a result, we can articulate limits within advertising practice, and evaluate claims about limit transgression. We argue that three important antecedents of contemporary body images - portraits, cartes de visite, and pin-up genres-play prominent roles in the production and consumption of identity, and limit the creative potential of advertising representation.

These ads share a conception of masculinity linked to consumer lifestyles. The images may reassure men by placing them in masculine situations-on a date with an attentive admirer, working at a managerial job, or kissing an attractive womenwhile subtly reminding them that this masculinity is tenuous, momentary, in need of constant stoking by consumer choice. Men have long been encouraged by advertising representations to take charge as consumers to construct flawless masculine 
identities. After all, consumer culture "depends on the continual creation and proliferation of 'defect,' that is always making us feel bad about ourselves at the same time it pumps us up with excitement over our own 'agency:' take charge, 'Just Do It!' etc." (Bordo 1997, 21). What is new about the advertising discourse are the expanded limits: aesthetics, emotion, and in the case of Aurora, displacement. Via advertising representation, the male body is being transformed into a visual object, and, as such, circulates in the same representational system as other visual objects, such as billboards, ads, and consumer goods. Thus, taken together, these images show how men can be represented as consumers, how the male body functions to represent consumer goals and in what ways ads articulate (masculine) desire via the male body.

The mirror remains a root metaphor of the consumer society, reflecting surface appearance, beckoning us to look, to compare, and to dream, and exposing us as exhibited objects for visual consumption. Like a fetish, mirrors express social psychological tensions, of appearance versus truth, for example, yet catch the viewer within a circuit of representation, vanity, and consumption (see Schroeder and Borgerson 2003). Moreover, these ad's use of advertising billboards—images within imagesimplicates them within a kind of funhouse mirror, endlessly reflecting consumer visions, perpetually displacing resolution, and continuously referring back on themselves in a parable of the consumption spectacle. In this way, the act of lookinglooking at products, others, oneself, ads, and images-reconfigures the subject of consumption.

When ads link male bodies with consumer goods they call upon a representational system that serves as a stabilizing, yet culturally and historically bounded "object-code" (McCracken 1988). Contemporary magazines seem to outsource heterosexual reassurance to the advertising and fashion images that play central roles in defining the publication's look, target market, and overall feel. We acknowledge that consumers are active agents in this process of meaning creation. However, structural elements such as sexual dualism in advertising and historical patterns of representation remain powerful influences. This interaction may have caused the advertising discourse to subtly shift its representation of the male body.

One contribution consists in extending previous work on male representation into historical, ontological, and art historical realms, providing a necessary bridge between advertising meaning residing within managerial strategy or wholly subsumed by consumer response. This analysis is centered around heterosexual Anglo-American culture. More work is required to situate this reading for other cultures, particularly in light of the rise of global capitalism, which "makes it imperative for us to examine how notions of body aesthetics are transported cross-culturally" (Joy and Venkatesh 1994, 334). However, the images under consideration speak, we believe, to the global affluent consumer who is not so much marked by spatial location as by socio-cultural capital (King 1990). We call for further research that situates advertising and identity within the historical flow of images.

Our specific readings of the ads might give the impression of a dogmatic viewpoint. This should be addressed. Our interpretations are subjective, suggestive and informed 
by our quasi-archeological approach; many other routes are possible. A feminist reading might point to the ads' potentially transgressive gender messages or, equally, to their obstinate perpetuation of traditional gender roles; a Marxist interpretation would perhaps make reference to the alienation we feel in the face of seductive commodity aesthetics; a managerial study could isolate cognitive responses in an effort to chart the images' "effectiveness." We believe each of these positions have important claims to make and should be equally pursued. However, we disagree that because different readers have different interpretations, this logically means that images float in a sea of uncertainty. Rather, we point to the historical, ontological and visual influences discussed here as critical components of meaning formation, in particular the cultural constructions of gender that evade individual notions of agency, gender-blending, or gender dualism's collapse.

Gender remains central to the world of advertising and consumption-it is difficult to conceive of most products without male and female target markets. Clearly, "we do not yet live in a post-gender age" (Bordo 1997, 150). Furthermore, marketing-positioning, segmenting, targeting - technologically co-opts, creates and maintains differences in consumer lifestyle, thereby actively reproducing the status quo; gender is no exception.

A central unresolved issue concerns how visual conventions affect perceptions. These ads are spectacular combinations of old and new representational systems, or what has been called "complicated contemporaneity" (Polan 1986). Understanding and acknowledging the visual past of advertising outlines one path to greater understanding about advertising as a representational and communicative system. However, the ontological status of advertising is not yet codified within the various discourses that it interacts with, such as art, photography, and the mass media. We believe that our genealogical approach contributes necessary context to the reading of advertisements.

The interactions of identity, consumption, and representation represent one of the critical imperatives of contemporary consumer culture. As global markets develop, built with global advertising campaigns, representations of identity promote a vast array of products to a burgeoning range of consumers. Cultural conceptions of gender identity, sexual fulfillment, and their part in the promised good life of consumer choice will come under intense pressure. Understanding the role that masculinity-and femininity_plays in consumption, visual history, and representation signals a step toward understanding how the market structures and subsumes basic ontological concerns of being, desire, and identity.

\section{Acknowledgements}

An early version of the paper was presented at the 1999 Association for Consumer Research Conference. Thanks to Janet Borgerson, Torsten Ringberg, Ozlem Sandikci and Árni Sverisson for comments on this project, and also to the anonymous reviewers for their excellent, constructive suggestions. The first author gratefully acknowledges support from the Jan Wallanders and Tom Hedelius Foundation. 


\section{Note}

[1] We employ the term masculinity as "a more or less symmetrical pendant to the concept of femininity developed within feminist theory. In other words, masculinity is, like femininity, a concept that bears only an adventitious relation to biological sex and whose various manifestations collectively constitute the cultural, social, and psychosexual expression of gender" (Solomon-Godeau 1995, 71).

\section{References}

Bajac, Quentin. 2002. The invention of photography: The first fifty years. Translated by Ruth Taylor. London: Thames \& Hudson.

Barthel, Diane. 1988. Putting on appearances: Gender and advertising. Philadelphia: Temple University Press.

Barthes, Roland. 1981. Camera Lucida: Reflections on photography. Translated by Richard Howard. New York: Noonday.

Bartky, Sandra Lee. 2002. "Sympathy and solidarity" and other essays. Lanham, MD: Rowman \& Littlefield.

Belk, Russell W. 1988. Possessions and the extended self. Journal of Consumer Research 15: 139-68.

Bender, Henning. 1982. Portraits by Heinrich Tønnies. In The frozen image: Scandinavian photography. New York: Abbeville.

Berger, Arthur A. 1998. Seeing is believing: An introduction to visual communication. Mountain View, CA: Mayfield.

Berger, John. 1972. Ways of seeing. London: Penguin.

Bordo, Susan. 1993. Unbearable weight: Feminism, western culture, and the body. Berkeley: University of California Press.

- 1997. Twilight zones: The hidden life of cultural images from Plato to O.J. Berkeley: University of California Press.

Borgerson, Janet L. 2001. Feminist ethical ontology: Contesting "the bare givenness of intersubjectivity." Feminist Theory 2: 173-87.

Borgerson, Janet L., and Jonathan E. Schroeder. 2002. Ethical issues of global marketing: Avoiding bad faith in visual representation. European Journal of Marketing 36: 570-94.

Bourdieu, Pierre. 1984. Distinction-A social critique of the judgement of taste. Cambridge, MA: Harvard University Press.

- 1992. Thinking about limits. Theory, Culture and Society 9: 37-49.

- 2001. Masculine domination. Translated by Richard Nice. Oxford: Polity.

Bristor, Julia M., and Eileen Fischer. 1993. Feminist thought: Implications for consumer research. Journal of Consumer Research 19: 518-36.

Brod, Harry. 1996. Pornography and the alienation of male sexuality. In Rethinking masculinity: Philosophical explorations in light of feminism, edited by Larry May, Robert Strikwerda, and Patrick D. Hopkins. Lanham, MD: Rowman \& Littlefield.

Burgin, Victor. 1996. In/different spaces: Place and memory in visual culture. Berkeley: University of California Press.

Butler, Judith. 1990. Gender trouble: Feminism and the subversion of identity. New York: Routledge.

-1993. Bodies that matter: On the discursive limits of "sex." New York: Routledge. . 1999. Subjects of desire: Hegelian reflections in twentieth-century France. Originally published in 1987. New York: Columbia University Press.

Callen, Anthea. 2002. Ideal masculinities: An anatomy of power. In The visual culture reader, edited by Nicholas Mirzoeff. New York: Routledge.

Clark, Danae. 2000. Commodity lesbianism. In The gender and consumer culture reader, edited by Jennifer Scanlon. New York: New York University Press.

Clarke, Graham. 1997. The photograph. London: Oxford University Press. 
Connell, Robert W. 1992. A very straight gay: Masculinity, homosexual experience and the dynamics of gender. American Sociological Review 57: 735-51.

- 2002 Gender. Cambridge: Polity.

Cooley, Charles Horton. 1902. Human nature and the social order. New York: Scribner's.

Drucker, Johanna. 1999. Who's afraid of visual culture? Art Journal 58: 36-44.

Dumm, Thomas L. 1993. The new enclosures: Racism in the normalized community. In Reading Rodney King: Reading urban uprising, edited by R. Gooding-Williams. New York: Routledge.

Dyer, Richard. 1982. Don't look now. Screen 23: 61-73.

Elliott, Richard, Susan Eccles, and Michelle Hodgson. 1993. Re-coding gender representations: Women, cleaning products and advertising's "new man." International Journal of Research in Advertising 10: 311-24.

Firat, Fuat A., John F. Sherry Jr, and Alladi Venkatesh. 1994. Postmodernism, marketing and the consumer. International Journal of Research in Marketing 11:311-16.

Foucault, Michel. 1977. Discipline and punish: The birth of the prison. Translated by Alan Sheridan. New York: Vintage Books.

- 1978. The history of sexuality. Translated by Robert Hurley. New York: Pantheon Books. - 1984. What is enlightenment? In The Foucault reader, edited by Paul Rabinow. New York: Pantheon Books.

Goffman, Erving. 1979. Gender advertisements: Studies in the anthropology of visual communication. New York: Harper and Row.

—. 1997 The Goffman reader. Malden, MA: Blackwell.

Goldman, Robert. 1992. Reading ads socially. London: Routledge.

Goldman, Robert, and Stephen Papson. 1996. Sign wars: The cluttered landscape of advertising. New York: Guilford.

Gombrich, E. H. 1999. The use of images: Studies in the social function of art and visual communication. London: Phaidon.

Gordon, Lewis R. 1995. Bad faith and antiblack racism. Atlantic Highlands: Humanities Press.

- 2003. Critical reflections on three popular tropes in the study of whiteness. In Unveiling whiteness: African American philosophical perspectives, edited by George Yancy. New York: Routledge.

Hackley, Chris. 2002. The panoptic role of advertising agencies in the production of consumer culture. Consumption Markets \& Culture 5: 211-30.

Hall, James. 1979. Dictionary of subjects and symbols in art. Boulder, CO: Westview.

Hall, Stuart. 1980. Encoding/decoding. In Culture, media, language, edited by Stuart Hall, Dorothy Hobson, Andrew Lowe, and Paul Willis. London: Hutchison.

— - ed. 1997. Representation: Cultural representations and signifying practices. London: Sage/ Open University Press.

Hanke, Robert. 1992. Redesigning men: Hegemonic masculinity in transition. In Men, masculinity and the media, edited by Steve Craig. London: Sage.

Hirschman, Elizabeth C. 1989. Role-based models of advertising creation and production. Journal of Advertising 18: 42-53.

Hirschman, Elizabeth, and Craig J. Thompson. 1997. Why media matter: Advertising and consumers in contemporary communication. Journal of Advertising 26: 43-60.

Holt, Douglas B. 1997. Poststructuralist lifestyle analysis: Conceptualizing the social patterning of consumption in postmodernity. Journal of Consumer Research 23: 326-50.

- 2003. What becomes an icon most? Harvard Business Review 80 (March): 43-49.

Joy, Annamma, and Alladi Venkatesh. 1994. Postmodernism, feminism and the body: The visible and invisible in consumer research. International Journal of Research in Marketing 11:333-57.

Kates, Steven M. 1999. Making the ad perfectly queer: Marketing "normality" to the gay men's community. Journal of Advertising 28: 25-37.

King, Anthony D. 1990. Global cities: Post-imperialism and the internationalization of London. London: Routledge. 
Kolbe, Richard H., and Paul J. Albanese. 1996. Man to man: A content analysis of sole-male images in male audience magazines. Journal of Advertising 25: 1-20.

Kuhn, Annette. 1982. Women's pictures: Feminism and cinema. New York: Routledge.

Lalvani, Suren. 1996. Photography, vision and the production of modern bodies. Albany: State University of New York Press.

Lears, Jackson. 1994. Fables of abundance: A cultural history of advertising in America. New York: Basic Books.

Leiss, William. 1983. The icons of the marketplace. Theory, Culture and Society 1: 10-21.

Leiss, William, Stephen Kline, and Sut Jhally. 1990. Social communication in advertising. Scarborough, Ontario: Nelson Canada.

Lippke, Richard. 1995. Radical business ethics. Lanham, MD: Rowman and Littlefield.

Lury, Celia. 1996. Consumer culture. Oxford: Blackwell.

Lury, Celia, and Alan Warde. 1997. Investments in the imaginary consumer: Conjectures regarding power, knowledge and advertising. In Buy this book: Studies in advertising and consumption, edited by Mica Nava, Andrew Blake, Ian MacRury, and Barry Richards. London: Routledge.

McCracken, Grant. 1988. Culture and consumption. Bloomington: Indiana University Press.

McQuarrie, Edward F., and David G. Mick. 1999. Visual rhetoric in advertising: Text-interpretive, experimental, and reader-response analyses. Journal of Consumer Research 26: 37-54.

Marchand, Roland. 1985. Advertising the American dream: Making way for modernity 1920-1940. Berkeley: University of California Press.

Miller, Daniel. 1995. Modernity: An ethnographic approach. London: Berg.

Miller, Toby. 1998. Commodifying the male body, problematizing "hegemonic masculinity?" Journal of Sport and Social Issues 22: 431-46.

Mirzoeff, Nicholas. 2002. The subject of visual culture. In The visual culture reader, edited by Nicholas Mirzoeff. New York: Routledge.

Mort, Frank. 1996. Cultures of consumption: Masculinity and social space in late twentieth century Britain. London: Routledge.

Mosse, George L. 1996. The image of man: The creation of modern masculinity. Oxford: Oxford University Press.

Mulvey, Laura. 1989. Visual and other pleasures: Theories of representation and difference. Bloomington: Indiana University Press.

Nixon, Sean. 1996. Hard looks: Masculinities, spectatorship and contemporary consumption. New York: St Martin's Press.

O'Donohoe, Stephanie. 2000. Reading advertising texts, understanding advertising consumption. In Interpretive consumer research, edited by Suzanne C. Beckmann and Richard H. Elliott. Copenhagen: Copenhagen Business School Press.

O'Guinn, Thomas. 2004. The elusive explanation of advertising. In Elusive consumption, edited by Karin Ekström and Helene Brembeck. Oxford: Berg.

Olin, Margaret. 1996. Gaze. In Critical Terms for Art History, edited by Robert S. Nelson and Richard Schiff. Chicago: University of Chicago.

Osgerby, Bill. 2001. Playboys in paradise: Masculinity, youth and leisure-style in modern America. Oxford: Berg.

Patterson, Maurice, and Richard Elliott. 2002. Negotiating masculinities: Advertising and the inversion of the male gaze. Consumption Markets \& Culture 5: 231-46.

Pelfrey, Robert, and Mary Hall-Pelfrey. 1993. Art and mass media. New York: Harper and Row.

Pennell, Greta E. 1994. Babes in toyland: Learning an ideology of gender. In Advances in consumer research, edited by Chris T. Allen and Deborah Roedder John. Provo, UT: Association for Consumer Research.

Polan, Dana. 1986. Brief encounters: Mass culture and the evacuation of sense. In Studies in entertainment: Critical approaches to mass culture, edited by Tania Modleski. Bloomington: Indiana University Press. 
Pratt, Mary Louise. 1992. Imperial eyes: Travel writing and transculturation. New York: Routledge.

Rizter, George. 1998. Introduction. In The consumer society, by Jean Baudrillard. London: Sage.

Rose, Nikolas. 1995. Authority and the genealogy of the subject. In Detraditionalization, edited by Paul Heelas, Scott Lash, and Paul Morris. Oxford: Blackwell.

1997. Inventing ourselves: Psychology, power and personhood. Cambridge: Cambridge University Press.

Schroeder, Jonathan E. 1998a. Consuming sexuality: A case study of identity marketing. In Gender, marketing and consumer behavior, edited by Eileen Fischer and Daniel Wardlow. San Francisco: San Francisco State University.

- 1998b. Consuming representation: A visual approach to consumer research. In Representing consumers, edited by Barbara B. Stern. New York: Routledge.

- 2002. Visual consumption. New York: Routledge.

. 2003. Gender, consumption and identity. Consumption Markets \& Culture 6: 1-4.

Schroeder, Jonathan E., and Janet L. Borgerson. 1998. Marketing images of gender: A visual analysis. Consumption Markets \& Culture 2: 161-201.

. 2003. Dark desires: Fetishism, ontology and representation in contemporary advertising. In Sex in advertising: Perspectives on the erotic appeal, edited by Tom Reichert and Jacqueline Lambiase. Mahwah, NJ: Lawrence Erlbaum Associates.

Scott, Linda A. 1994. Images of advertising: The need for a theory of visual rhetoric. Journal of Consumer Research 21: 252-73.

Sennett, Richard. 1977. The fall of public man. New York: Penguin.

Solomon, Michael R. 1999. Consumer behavior: Buying, having and being. Upper Saddle River, NJ: Prentice Hall.

Solomon-Godeau, Abigail. 1995. Male trouble. In Constructing masculinity, edited by Maurice Berger, Brian Wallis, and Simon Watson. New York: Routledge.

Stern, Barbara B. 1993. Feminist literary criticism and the deconstruction of ads: A postmodern view of advertising and consumer research. Journal of Consumer Research 19: 556-66. . 1996. Textual analysis in advertising research: construction and deconstruction of meanings. Journal of Advertising 25 (3): 61-73.

- 2003. Masculism(s) and the male image: What does it mean to be a man? In Sex in advertising: Perspectives on the erotic appeal, edited by Tom Reichert and Jacqueline Lambiase. Mahwah, NJ: Lawrence Erlbaum Associates.

Stern, Barbara B., and Jonathan E. Schroeder. 1994. Interpretive methodology from art and literary criticism: A humanistic approach to advertising imagery. European Journal of Marketing 28: $114-32$.

Sturken, Marita, and Lisa Cartwright. 2001. Practices of looking: An introduction to visual culture. Oxford: Oxford University Press.

Sturrock, Fiona, and Elke Pioch. 1998. Making himself attractive: The growing consumption of grooming products. Marketing Intelligence \& Planning 16: 337-43.

Tagg, John. 1989. The burden of representation: Essays on photographies and histories. Minneapolis: University of Minnesota.

Thompson, Craig J., and Diane L. Haytko. 1997. Speaking of fashion: Consumers' uses of fashion discourses and the appropriation of countervailing cultural meanings. Journal of Consumer Research 24: 15-42.

Thompson, Craig J., and Elizabeth C. Hirschman. 1995. Understanding the socialized body: A poststructuralist analysis of consumers' self-conceptions, body image, and self-care practices. Journal of Consumer Research 22: 139-53.

Tseëlon, Efrat. 1995. The masque of femininity. London: Sage.

Urry, John. 2002. The tourist gaze. 2nd ed. London: Sage.

Volpe, Andrea. 1999. Cheap pictures: Cartes de visite and visual culture in the U.S., 1860-1877. $\mathrm{PhD}$ diss., Rutgers University. 
2000. Cartes de visite portrait photographs and the culture of class formation. In The middling sorts: Explorations in the history of the American middle class, edited by Burton S. Bledstein and Robert D. Johnston. New York: Routledge.

Wardlow, Dan, ed. 1996. Gays, lesbians, and consumer behavior. San Francisco: Haworth.

Weiss, Gail. 1999. Body images: Embodiment as intercorporeality. New York: Routledge.

Williamson, Judith. 1978. Decoding advertisements. New York: Marion Boyers.

- 1986. Women is an island: Femininity and colonization. In Studies in entertainment: Critical approaches to mass culture, edited by Tania Modleski. Bloomington: Indiana University Press.

Willis, Susan. 1991. A primer for everyday life. London: Routledge.

Young, Iris M. 1990. Throwing like a girl and other essays in feminist philosophy and social theory. Bloomington: Indiana University Press.

Zwick, Detlev, and David L. Andrews. 1999. The suburban soccer field: Sport and the culture of privilege in contemporary America. In Football in the making: Developments in the world game, edited by Gary Armstrong and Richard Giulianotti. London: Macmillan. 
Copyright of Consumption, Markets \& Culture is the property of Routledge, Ltd. and its content may not be copied or emailed to multiple sites or posted to a listserv without the copyright holder's express written permission. However, users may print, download, or email articles for individual use. 